\title{
UNDERSTANDING PROFESSION IDENTITY OF JUNIOR HIGH SCHOOL COUNSELOR IN MALANG CITY
}

\author{
Arbin Janu Setiyowati ${ }^{a}$ \\ Department of Guidance and Counseling, Faculty of Education, Universitas Negeri Malang, Indonesia
}

Corresponding e-mail: Arbin.janu.fip@um.ac.id

\begin{abstract}
This study aims at acquiring the understanding of profession identity of Junior High School Counselor within Malang City. This study used qualitative design using phenomenology approach. The result of this study revealed that 1) counselor comprehend their role and capacity as a form of responsibility, devotion, and the pursuit of value in facilitating students' growth. 2) Counselor comprehends their characteristic as a counselor as an essential and positive trait within guidance and counseling service. 3) Counselor establishes social relation through initiative and consented interaction to the whole school community and related stakeholder. 4) Counselor apprehends their role and capacity in terms of consistency and parallelism of attitude. 5) The counselor is aware upon professionalism enhancement within themselves. 6) The motive, culture, experience, religious value, and background of the Counselor prevail upon their profession identity. The aforementioned results would be further argued and reviewed along with the findings obtained.
\end{abstract}

Keywords: profession identity; junior high school counselor

\section{INTRODUCTION}

In taking up their occupation counselor is expected to be able to accomplish their profession within themselves in terms of counselor profession spectrums such as basic knowledge, substantive profession, and practical profession. These three aforementioned spectrums could assure profession existence and construct counselor as a reputable profession. Counselor, as a helper profession, is imperative to improve positive public trust and perception [1]. To obtain positive public trust and perception, the counselor is highly suggested to maintain their finest and optimum performance during counseling. The attained public trust and perception are important since it dominantly exert an influence over the profession itself [2]

Within the attempt of the counselor in obtaining public trust from the related stakeholder, it is inevitably influenced by how the counselor apprehends their circumstance particularly on how they understand themselves in a professional insight. The ability of counselor in apprehend and understand themselves holistically is indicated by having a positive behavior, attitude, and thought as well as an adaptive personality within counseling process. This ability, however, relies dominantly on how counselor reflects upon themselves and profession. In fact, the ability of counselor to have a reflective thought upon their profession and themselves assists the counselor in discovering their limitation and their relation to another profession [3].

Several previous studies have argued that counselor belongs to the disreputable profession in comparison with a teacher in the classroom. Some even expressed that the position of the counselor in school is only an academic support although guidance and counseling field has evolved over the years and increasingly clarified school counselors' job roles and activities $[4 ; 5 ; 6 ; 7]$. The abovementioned stereotype and inferior paradigm upon counselor as a profession, in fact, is not only believed by people and school but also the counselor himself. The moment the counselor lack of pride upon their profession, it negatively contributes to the performance of counselor in conducting guidance and counseling program in school. The inability of the counselor in apprehending and understanding their profession identity contributes to the negative stigma and paradigm towards guidance and counseling among the people.

Thus, it is considered as a necessity for the counselor in apprehending and understanding profession identity. Well-built profession identity within the counselor would enhance and encourage the counselor in having a well-performed competency in conducting a professional guidance 
and counseling service [8]. In addition, total comprehension of counselor would enable counselor to develop them as a qualified helper. The moment the counselor possesses a well-built profession identity within themselves it makes a guidance and counseling program in the school have a similar degree with the academic program in supporting students' development.

Several approaches and attempts of guidance to the counselor were conducted to improve the performance and professionality of the counselor. One approach is In-service training. In-service training is expected to improve the quality of counseling as well as legitimacy from the user of counseling profession (in this case students and their parents). In fact, students have a less interest to utilize counseling service program. They commonly consider that counseling service program as the last source of an alternative to assist them. In addition, the fact exposed that some parents also put a less consideration towards the existence of guidance and counseling program in the school. This circumstance happened due to less professionality possesses by the counselor in conducting the program. Some parents, unfortunately, could not distinguish the outcomes of guidance and counseling service program and learning teaching program.

Counselor's ability improvement lies on the assumptions saying that the success of guidance and counseling service program in the school which is determined by attitude, knowledge, and skill acquired by the counselor could be obtained through In-service training.

The counselor is a profession in which possesses an apparent and recognized assignment. it means that counselor possesses an assortment of assignment and responsibility which require an exceptional talent, ability, and skill in providing an assistance to the user, particularly the counselee. The degree of knowledge, ability, skill, and attitude comprehension within the provision of guidance and counseling indicate counselor professionalism. The improvement of counselor professionalism could be conducted through several means and approaches. This improvement is expected could assist and help counselor in improving their performance and successfully managing professionalism. In fact, during the attempt to improve the performance of counselor, it requires a standard of competence within the counselor as an elemental measurement of counselor professionalism attainment.

It is essential for the counselor to apprehend their profession identity as an elemental basis in providing guidance and counseling service professionally. Counselor apprehension upon profession identity is connected with profession organization support and protection towards counselor in the field. Profession organization support and protection encourages the counselor in achieving performance satisfaction and successful counseling practice conducted [9].

Counselor profession identity development and encouragement is partially supported by the existence of the professional association. Formal objective of the professional association is to establish a platform for general profession essentiality, enforce professional development through research, perform as a professional representative, provide forum concerning on skill and knowledge enhancement of counselor, and function as a channel for improving professional performance [10]. In Indonesia, the presence of ABKIN as a professional association of guidance and counseling service is expected to take a prominent role in facilitating counselor to develop their professional performance and as a result, the counselor is able to grow into a competence counselor.

An outright model of counselor competency includes academic competence and professional competence. The two competencies are inseparable. Academic competence functions as scientific basis of professional counseling service provision and basis of professional competence which includes (1) in-depth understanding of counselee assisted, (2) acquiring counseling basis and theoretical framework, (3) providing an independently assisting counseling service, and (4) developing perpetual professionality within the counselor [11]. The counselor performance dominantly relies on the acquisition of the four above-mentioned competencies along with value, attitude, and the characteristic within the counselor.

Profession identity apprehension within the counselor is connected with the positive relationship among the counselors. The essential function of the counselor as an assistant of guidance and counseling service is to provide a trustworthy and straightforward feedback to the counselee. Serving as an assistant in guidance and counseling service, counselor requires understanding the dynamics of personality, therapeutic process, as well as their personality and attitude since guidance and counseling service is a related and connected to one and another. Effective counseling relation to a certain extent is influenced by the relation quality of the counselor among their co-workers. It is inevitable, thus, that conducive working environment positively influences the successful of guidance and counseling service.

Counselor profession identity could be identified from how (a) counselor performs and (b) counselor approaches in conducting a counseling [12]. It is imperative to understand how counselor 
defines and fulfill their role such as professionalism, attitude, the approach used, capacity, and function as well as how they identify themselves. In other words, the counselor should understand that they are the model of the entire professional occupation conducted.

According to the above-mentioned issue, it can be derived that profession comprehension of the counselor is important and influence the performance guidance and counseling service in the school. Counselor requires understanding comprehensively their role and capacity as a means for exploring their talent in providing a guidance and counseling service in the school. This study aims at discovering how school counselor, particularly within Junior High School, understand their profession identity seen from (1) the role and function of profession, (2) the characteristic of counselor personality, (3) the ability in establishing social relationship, (4) the role model as counselor, (5) the improvement of professional competence.

\section{METHOD}

This study used a qualitative approach and descriptive phenomenology design. Within this qualitative approach, the researcher performs as a primary research instrument. The researcher serves as a prominent participant in obtaining data related to the objectives of this study through an in-depth interview with the research subject. The presence of the researcher, therefore, is imperative within the location of study in order to establish a good relationship with the subject of this study during the process of obtaining data.

Before this study was conducted, several presurvey was done to obtain several accurate information regarding examined topic. Pre-survey was conducted through the preliminary interview. After the preliminary review was conducted, an indepth interview was done to the observed subject to accomplish the objectives of this study. In this study, the researcher performs as the instrument and data collector. The location and subject of this study were determined purposively.

The subject of this research is three counselors from one Junior High School in Malang. The obtained data of this study was analyzed through phenomenology procedure with the following steps of data reduction, data display, data verification, and conclusion drawing. To secure the validity of the data obtained, then several validity tests were conducted such as credibility, dependability, and confirmability.

\section{RESULTS}

This part exposes comprehensively the findings of this study includes (1) the role and function of the profession, (2) the characteristic of counselor personality, (3) the ability in establishing a social relationship, (4) the role model as a counselor, (5) the improvement of professional competence.

\section{The Role And Function Of Profession}

Variables which are pertaining to the role and function of the profession are: (1) counselor performance exposed is an assignment which is responsible for facilitating the students upon the optimum development of their entire life aspects. (2) counselor understands their role as a part of academic stakeholder within the school who take a prominent part in establishing a conducive environment of school as well as the teachers and another stakeholder. (3) the function of the counselor is to ensure the character development of the students. (4) counselor sees their function is a moral obligation in creating a better human being. (5) guidance and counseling service in the school serves as a part of religion value application.

\section{The Characteristic Of Counselor Personality}

Variables which are pertaining to the role and function of the profession are: (1) counselor personal attitude exposed is a spontaneous attitude which is based on heartfelt and sincere feeling to assist and guide the counselee in surviving within the counselee lowest point of life. (2) in giving a guidance and counseling in the school, the counselor provides it based on a warm-hearted relationship and communicative with all related stakeholder. (3) the counselor believes that guidance and counseling service in the school is a humanity action which relies on the ability of the counselor in controlling and managing their emotion. (4) the counselor pays a meticulous attention regarding students' development and (5) counselor takes into account any approaches to improve the quality of their personality continuously.

The Ability In Establishing Social Relationship

In accordance with the counselor perspective, it is important to be proficient in establishing a social relationship with all stakeholder related to the development of the students. Variables which are pertaining to the ability in establishing social relationship are (1) counselor initiative and consent 
to interact with all school's member without exception. (2) the number of students who are interested in attaining guidance and counseling service. (3) the development of cooperation which is conducted.

\section{The Counselor Role Model}

The role model as counselor means that the counselor should be able to recognize personally and take into account guidance and counseling standard ethics. Counselor personal characteristic is also essential within the role model of a counselor. The role of the counselor as an ideal model of a good attitude in both school and society demands them to manage and keep their appearance, attitude, and the way of communicating to the students and every stakeholder in the school. In addition, the counselor is demanded to show positive behavior to the students as a role model. The counselor is also demanded to be able to manage the personality in every situation as well as managing any actions conducted.

Variables which are pertaining to the counselor as a role model are: (1) the perspective of school's members which recognize counselor as a role model for the students since the counselor deals in guiding students' behavior. (2) counselor awareness upon proper behavior conducted in school. (3) counselor attempt in synchronizing attitude exposed in everyday life and what is delivered to the students.

\section{The Improvement Of Professional Competence} Variables which are pertaining to the improvement of professional competence are (1) self-examination attempt to improve personal quality through any approaches of learning. (2) Counselor attempts to learn the development of knowledge related to guidance and counseling service through the active participation in MGBK, seminar, and workshop. (3) Counselor attempts to learn information technology within guidance and counseling service through training, peer tutorial, and share learning with the students.

\section{DISCUSSION}

Guidance and counseling service in school is integrated within the school's system and the whole education system. It is undeniable that guidance and counseling service in school is required for facilitating optimum development and growth of the students regarding the entire life aspects. To accomplish the above-mentioned objective, counselor indeed takes a prominent role within the school and it shall be regarded as a reputable and important occupation.

Generally, professional service of guidance and counseling is organized through any approaches based on knowledge basis, technology, and value to escalate public trust of the counselor. In responding the above-mentioned, therefore, several qualifications are paramount within professional counselor. The qualifications desired include both academic and professional competence. Both abovementioned components are indeed inseparable.

In accordance with the purpose of being a counselor, the findings obtained indicated that the counselor chose to counsel as primary occupation aroused by humanity feeling within the counselor as well as encouraged by religion value and professional paradigm. Within the angle of a counselor who aroused by the sense of humanity feeling believed that being a counselor is exclusive which every individual could pursue one. An only distinct individual who possesses a peculiar personal characteristic could manage to become a counselor. Indeed, a distinct individual should be able to completely act compassionately within the service to assist the counselee in sustaining any dilemma and complication existed. Supplementary, personal encouragement within the counselor influence how the counselor contributes to the surrounding circumstance.

Afterward, counselor purpose aims essentially at assisting others in solving their problems. Counselor postulates a belief that counselor's role and capacity are desired for people in assisting them to survive within their dilemma and complication happened in their life as well as develop their personal competence and potency. Further, personal satisfaction occurs within people who obtain an assistance from the counselor. This personal satisfaction encourages counselor to consistently assist people in the future.

Another purpose which the counselor intended to accomplish is to actualize religion value they believed. Counselor postulates a belief that being a counselor is a form of religion worshiping and the way human actualize God's commandment. Counselor, further, believes that religion value actualization should not be limited only to the vertical relationship between human being and The Divine Being. Instead, religion value actualization should also be committed within human being relationship and both should be actualized in a balanced portion. Counselor, supplementary, regards 
that as a human being they require taking a role in accentuating good deeds within the human being and the environment.

Counselor understanding referring to professional occupation reckons that the counselor profession is circumscribed only to the limited individual. Pursuing counselor profession requires both academic and professional competence which is obtainable through an education in a formal institution as well as attained know-how in the field regarding counseling. Academic competence which is required to be possessed deals with theoretical proficiency and comprehension while attained know-how comes across with direct experience faced by the counselor.

Counselor's job is responsible for providing a professional service to the user (counselee) and hence, the counselor needs to acquire broad and encyclopedic knowledge regarding counseling as well as other pertinent knowledge to counseling. Before pursuing a career as a counselor, the individual needs to satisfy all requirements in terms of education and experiences. Wrapping up the above-mentioned statements, the counselor is expected to possess essential, practical, and considerable skill and experience to be able to provide guidance and counseling service and assist counselee's development.

In accordance with research findings, it can be concluded that counselor properly understands their role and function as a counselor. In addition, counselor recognizes that their primary role and function is to facilitate students as a counselee within their life aspect development. Moreover, counselor also takes a function along with the entire staffs and members of the school in establishing a conducive circumstance of school for the students. Therefore, the role and function of counselor within the school considered substantial for supporting students development.

Also, according to the findings on counselor personality, it can be concluded that counselor possesses a decent personality which supports their profession as a counselor and able to identify both limitations and preeminences within the personality. Both personality and professional attitude of counselor take a pivotal role in facilitating and assisting the counselee. Okun and Katriwiz in [13] remark that it is difficult to distinguish between personality and professional sphere of counselor since both are connected.

The professional counselor will continuously to have an inner-directed analysis in line with values, thought, and feeling towards themselves and reflect every single provision and assistance they conducted. In addition, the counselor must acquire a skill on counseling. Skill also plays as a climatic element within counseling since they are regarded as an individual who possesses a decent knowledge and acquires sufficient information to conduct any analysis within the provision of guidance and counseling.

As revealed in the research findings regarding the ability of counselor in establishing a social relationship, the counselor is able to establish a harmonious relationship. Since counselor takes an imperative role in the school in assisting the students as a counselee and ensuring their development, hence, the ability of social relationship is expedient within counseling process. In addition, counselor requires undertaking as an intermediary between students and parents, as well as parents and school. further, as a professional and proficient contributor, the counselor is demanded to be competent in developing and conducting guidance and counseling service which is able to accommodate all related stakeholder necessity and subsequently, it reconstruct a negative stigma within guidance and counseling service in the school.

As obtained in the field observation, it indicates that counselor establishes a fine relationship among the co-workers. Satisfyingly, each individual within the school feels that they are inseparable and dependable to one another in conducting guidance and counseling service. This condition indeed contributes to the quality of professional function of counselor and undeniably resulted in the quality of counseling. Further, the aforementioned condition is parallel with the general assumption regarding social identity concept suggested by Tajfel in [14] remarks that (1) individual will constantly elevate their selfesteem and attempt to establish and construct a positive characteristic. (2) A group or social category of themselves is associated with positive or negative value connotation. Social identity might be positive or negative based on the group evaluation (according to the social consent even cross-group environment) which contributes to the individual social identity. (3) The evaluation within particular group aims at determining the group and also functioning as a specific reference to another group through social comparison in the form of attribute value or characteristic attached.

As observed in the field regarding counselor ability in establishing a social relationship to the entire stakeholder, particularly among students, a counselor could establish a fine and harmonious relationship within the service provision. According 
to Akos and John [15], school community such as School's Principal, teachers, students, staffs, and parents as well as other related stakeholder promote a favourable and stimulating environment for career development, personal and social competencies in the future. Hence, to bring the aforementioned conditions prevailed, the counselor needs to activate their initiative and eagerness to manage good relationship and cooperation with the entire stakeholder which is related to the improvement quality of guidance and counseling service.

Within the context of the relationship among students, counselor, particularly, needs to be able to adapt accordingly their thinking pattern to the youth attitude by recognizing their circumstance and world. Further, the counselor is demanded to be active in any school's activity directed to the students. This would be potentially effective to establish a fine relationship with the students instead of having a passive involvement and just waiting for students to come.

According to the field observation, counselor understands that society or their surrounding environment set up an expectation to be able to expose a consistent positive attitude and behavior. Further, since counselor deals with students guidance and counseling, it is essential for counselor in exposing a positive attitude and behavior consistently. Subsequently, guidance and counseling service to the students will be effective the moment the counselor is able to be an excellent role model. When the counselor is able to understand and apprehend their profession identity, guidance and counseling service will undoubtedly become an advantageous part of school development service.

Also, the field observation regarding the improvement of professional competence indicated that counselor is aware of the need to improve professional ability. Satisfyingly, counselor actively improves their professional competence through any approaches as well as inner-directed reflection. In addition, it is essential to conduct any approaches to strengthen their professional competence and provide a channel for them to develop. Above all, eagerness and creativity are the key of the counselor in improving the professional competence.

In conducting guidance and counseling service in school, the counselor will doubtless interact with a diverse characteristic of students. In addition, students of junior high school is an adolescent who experiences a set of powerful and extreme changes within themselves in terms of cognitive, emotion, and social [16]. This condition suggests a counselor to be able to be creative and proficient to handle the traits possesses by junior high school students and finally they are regarded as a reliable person to assist any hindrance and deterrent within their life.

The creative counselor will doubtlessly be able to find any approaches for providing an optimum counseling. Subsequently, guidance and counseling service in school could perform as a proper and effective channel to facilitate the students' development in terms of personality, social, and academic.

The understanding of profession identity by counselor will also promote an understanding of fellow counselor and society upon the profession of a counselor. This understanding is important to assist organization of profession to understand exceptional professional traits and characteristics of their respected members [17]. Therefore, it is expected for the organization of profession to give their contribution through establishing a foundation in terms of advocacy, acknowledgment rights, and active involvement in promoting the legitimacy of counselor within professional circumstance [18]. Legitimacy acknowledgment of the counselor in professional circumstance will assist and alleviate the professional performance of the counselor as well as dealing with the hindrances.

\section{CONCLUSION}

In accordance with research objectives, the obtained data and findings, and its analysis as well as the discussion of the obtained data, several points could be generated as a conclusion. (1) Counselor understands and apprehend their role and function as a profession which directed and concerned to the counselee welfare. This, further, relies on how counselor apprehends professional value as counselee, responsibility, humanity value to assist the counselee, as well as religion value attached. (2) Counselor understands and apprehend their personal characteristics within their professional occupation as a foundation attitude of counselor which positively implemented within the service and subsequently generate a public trust and satisfaction from the users of guidance and counseling service (counselee). (3) Counselor maintains positively the ability in establishing a social relationship. It is indicated by the counselor's initiative in having a fine and harmonious relationship with the entire members of school's community with no exception. In addition, it is showed by the number of students who seek for an assistant to the counselor and cooperation development with related stakeholder. 
(4) Counselor understands their consistent behavior as an essential point which performs as the role model for the students. (5) Counselor understands and is aware of the improvement quality of their professional performance as an essential element which needs to be done continuously. In this context, counselor attempts to consistently have inner-directed reflection regarding their quality and resolve the hindrance which may influence their performance to accomplish a qualified service of guidance and counseling. (6) At the end, personal motive and rationale, culture, religion value attached, as well as personal background directly influence the understanding and apprehension of counselor regarding profession identity.

According to the findings and discussion above, several points could be generated as suggestions. (1) It is suggested for the school counselor to be able to imitate and identify themselves within the provision of professional guidance and counseling service. (2) It is suggested that organization of profession or ABKIN facilitate a role and function clarification of counselor profession seen from a practical perspective which focuses on the professional identity of education counselor. (3) It is expected for education institution of the counsellor in facilitating the candidate of the counsellor in developing profession identity as a professional education counselor.

\section{REFERENCES}

[1] U. Gale and B. D. Austin. "Professionalism's challenges to professional counselors' collective identity", Journal of counseling \& development, vol 81, 3-10, 2003. doi: 10.1002/j.1556-6678.2003.tb00219.x

[2] T. E. Bradley. Professional School Counseling A Handbook of Theories, Programs \& Practices. Texas: PRO-ED An International Publisher, 2004.

[3] E. Neukrug. The world of the counselor: An introduction to the counseling profession (3rd ed.). Belmont, CA: Brooks-Cole, 2007.

[4] J. J. Burnham and C. M. Jackson. "School counselor roles: discrepancies between actual practice and existing models", Professional school counseling, 4, 41-49, 2000.

A. Cervoni and J. DeLucia-Waack. "Role Conflict and Ambiguity as Predictors of Job Satisfaction in High School Counselors", Journal of school counseling, 9(1), 2011. Retrieved from http://www.jsc.montana.edu/articles/v9n1.pdf
[5] M. A. Shillingford and G. W. Lambie. "Contribution of professional school counselors' values and leadership practices to their programmatic service delivery", Professional school counseling, 13, 208- 217, 2010. doi: 10.5330/PSC.n.2010-13.208

[6] C. Trolley. "School Counselor Roles and Preparation", Michigan journal of counseling, 38, 15-22, 2011.

[7] S. L. Yeo, and Y. S. Tan and F.M. Neihart. "Counseling in Singapore", Journal counseling and development, 90(2), 243-248, 2012.

[8] G. M. Darcy and M. N. Abed - Faghri. "The relationship between counselors and their state professional association: exploring counselor professional identity", The professional counselor 3(3), 152-160, 2013.

[9] American Counseling Association. 20/20 Statement of Principles Advance The Profession, 2009. Retrieved from HTTP:// www.counseling.org/news/news-releasearchives/by-year/2009/2009/01/20/20-20statement-of-principles-advances-theprofession

[10]Depdiknas. Penataan Pendidikan Profesional Counselor Dan Layanan Bimbingan dan konseling dalam Jalur Pendidikan Formal. Jakarta: Departemen Pendidikan Nasional, 2008.

[11] V. D. Machorro and A.T. "Suck. Professional identity of counselor in mexico: a commentary", The professional counselor journal, vol 4(1), pp 84-92, 2014. Doi: $10.15241 / \mathrm{vdm} .4 .1 .84$

[12]M. A. Hogg and G. M. Vaughan. Social Psychology (3rd ed. ). London: Prentice Hall, 2000.

[13]R. Barunda and L. Rolla. "Lived stories: participatory leadership in school counseling", Journal of counseling \& development, 84, 406413, 2006.

[14] P. Akos and G. John.” Development advocacy: twenty_first century school counseling", journal of counseling and development: JDC; Spring: 82,2, 2004.

[15]R. Fagan. "Counseling and treating adolescents with alcohol and other substance use problem and their family", The family journal: counseling therapy for couples and families. 14(4), 326.333, 2006. SAGE Publication.

[16] J. E. Myers and T. J. Sweeney and V. E. White. "Advocacy for counseling and counselors: A professional imperative", Journal of counseling \& development, 80, 394-402, 2002. 
[17]F. M. Zimring. "Empathic understanding grows", The person, person-centered journal, $7(2), 101-113,2000$. 